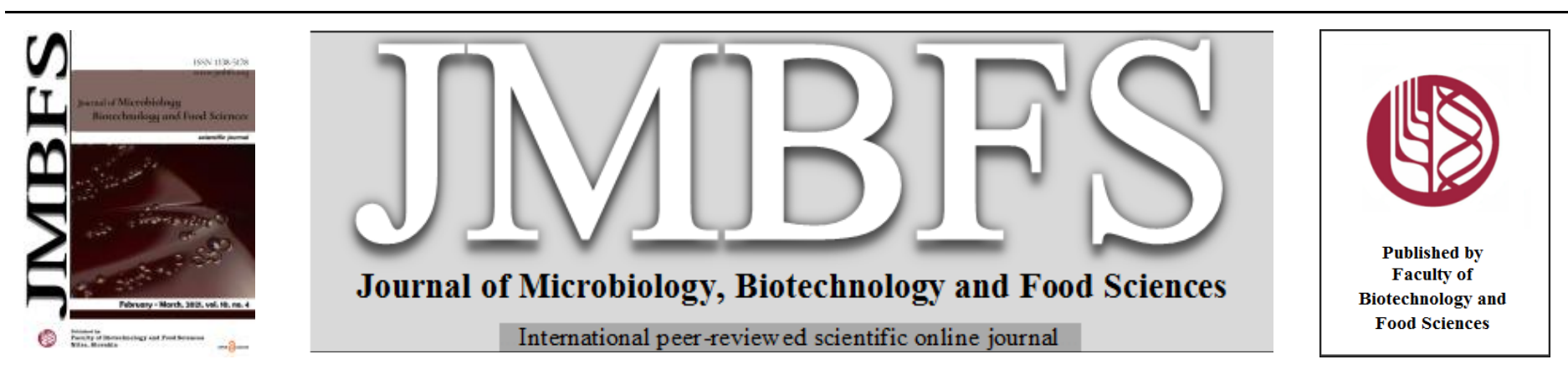

\title{
ISOLATION AND CHARACTERIZATION OF BIOACTIVE COMPOUNDS IN MEDICINAL PLANT Centella asiatica AND STUDY THE EFFECTS ON FUNGAL ACTIVITIES
}

\author{
Prakash Bhuyar, Mohd Hasbi Ab. Rahim, Gaanty Pragas Maniam, Natanamurugaraj Govindan*
}

Address(es): Dr. Natanamurugaraj Govindan,

Biotechnology Laboratory, Faculty of Industrial Sciences \& Technology, Universiti Malaysia Pahang, Lebuhraya Tun Razak, 26300 Gambang, Kuantan, Pahang, Malaysia.

*Corresponding author: natanam@ump.edu.my

doi: $10.15414 / j m b f s .2021 .10 .4 .631-635$

\section{ARTICLE INFO}

Received 21. 3. 2020

Revised 17. 10. 2020

Accepted 27. 10. 2020

Published 1. 2. 2021

Regular article OPEN OACCESS $_{\text {A }}$

\begin{abstract}
Medicinal plants are sources of important therapeutic aids for alleviating human ailments. The present research investigation was carried out to study anti-fungal activity of $C$. asiatica were tested against $C$. albicans, Aspergillus niger, and Penicillium sp. using two methods, disc diffusion method and broth dilution method. $C$. asiatica crude methanol extract was found to be the most effective against fungal activity. Compared to disc diffusion, broth dilution was a more appropriate method to quantitatively determine the anti-Candida activity of plant extract, whereby the MIC values of the crude extracts was determined. The result from disc diffusion assay demonstrates that plant extracts have an inhibitory effect. However, the broth dilution method result reveal that $C$. asiatica crude methanol extract has lower MIC values, meaning it has more prove that $C$. asiatica has an anti-fungal effect. Bioactive analysis results reveled that bioactive compounds present in the leaf, stems, roots, and the whole plant extract from Centella asiatica are the major chemical constituents are n-Hexadecanoic acid (99\%), cis-Vaccenic acid (91\%), 5-Hydroxymethylfurfural $(88 \%)$, Tetradecanoic acid (86\%). Further study is required to find out the specific phytochemical which is responsible for its medicinal value.
\end{abstract}

Keywords: Centella asiatica, GC-MS, bioactive compounds and phytochemical

\section{INTRODUCTION}

Despite tremendous progress in human medicines, infectious diseases caused by bacteria, fungi, viruses and parasites are still a major threat to public health (Bhuyar, 2017; Bhuyar et al., 2020a; Bhuyar et al., 2018). Their impact is particularly large in developing countries due to relative unavailability of medicines and the emergence of widespread drug resistance. Clinical microbiologists have great interest in screening of medicinal plants for new therapeutics (Saengsawang $\boldsymbol{e t}$ al., 2020). The active principles of many drugs found in plants are secondary metabolites. The antimicrobial activities of plant extracts may reside in a variety of different components, including aldehyde and phenolic compounds (Bhuyar et al., 2019a). The development of drug resistance in human pathogens against commonly used antibiotics has necessitated a search for new antimicrobial substances from other sources including plants (Bhuyar et al., 2020b). Hence the sensitivity study of bacterial strains to the plant Centella asiatica was evaluated.

Centella asiatica belongs to Apiaceae family and Centella genus. It is a tasteless, odorless plant that thrives in and around water. It has small fan-shaped green leaves with white or light purple-to-pink or white flowers and it bears small oval fruit. The whole plant is used for medicinal purposes (Loiseau et al., 2012). It is widely used as a blood purifier as well as for treating high blood pressure, for memory enhancement and promoting longevity (Jagtap et al., 2009). In Ayurveda, Centella asiatica is one of the main herbs for revitalizing the nerves and brain cells (Vogel $\boldsymbol{e t}$ al., 1990). Eastern healers relied on Centella asiatica to treat emotional disorders, such as depression, that were thought to be rooted in physical problems. In the Western medicine, during the middle of the twentieth century, Centella asiatica and its alcohol extracts reported to have shown positive results in the treatment of leprosy (Zainol et al., 2003).

Various well-known fungus causing fungal infections in humans. Candida albicans is an opportunistic pathogen typically colonizes the skin and mucosal epithelium of healthy individuals (Zainol $\boldsymbol{e t}$ al., 2008). In response to changes in the host environment, this yeast may become pathogenic causing various nonlife- threatening infections, such as oral thrush and vaginitis (Bhuyar et al., 2020). However, in cancer patients and immunosuppressed individuals, the yeast colonization may progress to invasion, resulting in severe systemic candidiasis. Invasive fungal infections are associated with high mortality rates and over $40 \%$ in bloodstream infections caused by Candida albicans (Cushnie et al., 2005).
Despite appropriate anti-fungal therapy, mortality from candidemia is over $30 \%$ (Bhuyar et al., 2020c). With the increasing number of immunocompromised patient population, these fungal infections are becoming more prevalent. In addition, $C$. albicans can also colonize various biomaterials, such as urinary and vascular catheters, and ventricular assist devices causing increasing incidence of candidiasis in hospital patients (Wang et al., 2006). Another fact is up to $75 \%$ of sexually active women have at least, at time experienced vaginal candidiasis, an inflammatory condition caused by yeast predominately $C$. albicans. This condition results in severe genital itching, vagina odor and abnormal discharge (Inamdar et al., 1996; Khammee et al., 2020).

Responding to this worldwide concern, the proposed research is carried out to analyze and characterized the specific bioactive component in Centella asiatica. For instance, a bioactive component produce can be used to analyze mechanism activity of fungal and bacteria by adding the extraction of $C$. asiatica. The proposed research is done to compare the effect of plant extraction and specific drug to the growth production of bacterial and fungal by monitoring mechanism activity of pathogen in agar plate and broth dilution. Having said this, obviously, the objective of this proposed research is to reduce costs in terms of buying external expensive drug and to efficiently safe use for human purpose as it come from natural sources chemical.

\section{MATERIAL AND METHODS}

Fungal and bacterial strain

The type strain of Candida albicans ATCC 10231, Aspergillus niger and Penicillium sp. tested is subculture on Sabouraud dextrose agar (SDA) and Potato dextrose agar (PDA). Then, incubated for $24 \mathrm{~h}$ at $37^{\circ} \mathrm{C}$. Inoculum obtained from the overnight agar culture.

\section{Preparation of plant crude methanol extract}

Centella asiatica were purchased from the local retail market. All plant materials washed thoroughly under running tap water and air dried at room temperature for two days and ground into a fine powder. The air-dried and powdered plant material are extracted with $400 \mathrm{ml}$ of $95.5 \%$ methanol, kept in the room temperature for $72 \mathrm{~h}$ with periodic stirring. Thereafter the extract was filtered by 
Whatman no 4. filter paper to remove the marc. The supernatant was collected and evaporated in a rotary evaporator under reduced pressure at a temperature of $64{ }^{\circ} \mathrm{C}$ (methanol bp) until an oily dark paste was formed then transferred to water bath to allow further evaporation of methanol. The plant extracts were stored in refrigerator at $-80^{\circ} \mathrm{C}$ for 2 days before transferred to freeze dry for further usage.

\section{Fungal inoculum preparation}

The inoculum is prepared using 24-hour plate cultures of Candida albicans, Aspergillus niger, and Penicillium sp. The inoculums were prepared by taking at least three to five well-isolated colonies of the same morphology with a sterile loop and transferred into a tube containing 4 to $5 \mathrm{ml}$ of Potato dextrose broth. The turbidity of the suspension is adjusted until it achieved the turbidity of the 0.1 McFarland standard (Bhuyar et al., 2019b). This resulted in a suspension containing approximately of 1 x $108 \mathrm{CFU} / \mathrm{ml}$. To aid comparison the test and standard are compared against a white background with a contrasting black line (Sampson et al., 2001).

\section{Antifungal Assay}

Antifungal assay used to study the plant extracts for antifungal activity. Firstly, the plant extracts are dissolved in methanol. Under aseptic conditions, $0.2 \mathrm{~mL}$ of standardized inoculum are spreaded on to sterile Sabouraud dextrose agar (SDA) plates and Potato dextrose agar (PDA) to achieve a confluent growth. The plates are then allowed to dry. Sterile filter paper discs of $5 \mathrm{~mm}$ diameter are loaded with $50 \mu \mathrm{L}$ of the methanolic extracts $(100 \mathrm{mg} / \mathrm{mL})$. The paper discs were allowed to evaporate and then placed aseptically on the surface of the inoculated agar plates. Standard Fluconazole and Nystatin $(30 \mu \mathrm{g})$ disc for antifunga activity were used as positive control while methanol $(30 \mu \mathrm{L} /$ disc $)$ are used as negative control. Plates were then incubated at $37^{\circ} \mathrm{C}$ for $24 \mathrm{~h}$. The experiment was performed in triplicates. At the end of the incubation period, the antifungal activity was measured by evaluating by zone of inhibition around each paper disc. The mean value of the diameter of the inhibition zone of the triplicates were selected as the final value.

\section{Determination growth rate}

The growth rate process is determined by broth dilution method as described by (Booncong, 2000). The fungal of Aspergillus niger, Penicillium sp. and Candida albicans were grown in Potato Dextrose Broth for overnight at $27^{\circ} \mathrm{C}$ temperature. The fungal sample was diluted until absorbance to get below than $0.1 \mathrm{Abs}$ Extracts of stems, roots, leaves, and whole plants reconstituted in $95.5 \%$ methanol was pipetted into cuvettes in each of sample is $30 \mu 1$ in concentration. Same procedure was followed with $1000 \mu$ l of fungal sample in Potato dextrose broth (PDB). Extract-free solution was used as a negative control. The growth rate measurement process (absorbance) was started with 0 second followed with 30 minutes interval until the growth rate in steady state.

The growth rate process will show the growing process of fungal in presence of inhibitor which is parts of Centella asiatica and other controls. The measurement of growth whether increase or decrease is observed in every 30 minutes. Minimum Fungicidal Concentration (MFC) used to determine if the plant extracts were fungistatic or fungicidal using (Hamid et al., 2002) method. To determine the growth rate, $1000 \mu \mathrm{L}$ of fungal broth collected (Aspergillus niger, Penicillium sp. and Candida albicans) and pipette into sterile cuvettes. After that, 30ul of extract sample (each fungal with four different sample of stems, roots, leaves, and whole plants) are pipette into the cuvettes. The absorbances are measure in every 30 minutes which they were observed for growth curve of fungus.

\section{Chemical Composition Analysis by GCMS}

To test the bioactive compounds, present, preliminary phytochemical analysis was carried out by using the standard method to identify the components in the various plants extracts of Centella asiatica. The methanol extracts of $C$. asiatica was subjected to the analysis of chemical components by gas chromatographymass spectrometer (GC-MS) (Ramli et al., 2020; Bhuyar et al., 2019b). A hightemperature column (Inert cap $1 \mathrm{MS} ; 30 \mathrm{~m} \times 0.25 \mathrm{~mm}$ id $\times 0.25 \mu \mathrm{m}$ film thickness) was used whereby a high- temperature column was applied. The injector and detector temperature were set at $280^{\circ} \mathrm{C}$ while the initial column temperature was set at $100^{\circ} \mathrm{C}$. A $5 \mu \mathrm{l}$ sample volume was injected into the column and ran using split $(1: 10)$ mode. After $1 \mathrm{~min}$, the oven temperature was raised to $225^{\circ} \mathrm{C}$ at a ramp rate of $12.5^{\circ} \mathrm{C} / \mathrm{min}$ (hold time $4 \mathrm{~min}$ ). The oven temperature was then raised to $300^{\circ} \mathrm{C}$ at a ramp rate of $7.5^{\circ} \mathrm{C} / \mathrm{min}$ (hold time $5 \mathrm{~min}$ ). The helium carrier gas was programmed to maintain a constant flow rate of $17.5 \mathrm{ml} / \mathrm{min}$ and the mass spectra were acquired and processed. Finally, the mass was compared with NIST library search and authentic standards to identify the compound (Borhan, et al., 2013).

\section{RESULTS AND DISCUSSION}

\section{Antifungal activity of Centella asiatica}

Antifungal activity determined by the disc diffusion assay as described by (Devi and Prabakaran, 2014) Antifungal activity of each plant extract was evaluated based on the diameter of the clear inhibition zone surrounding the paper discs. If there is no inhibition zone, it is assumed that there is no antifungal activity. Table 1,2 and 3 shows the antifungal activity of stems, roots, leaves, and whole plant methanol extract against Candida albicans, Aspergillus niger, Penicillium sp. At the end of the analyses, all the plant extracts were found to have an inhibitory effect against the tested fungi strain. The potency and activity of antifungal is usually determined by zone of inhibition on agar plates. Inhibitory activity of the paper disc diffusion test revealed that the crude methanolic extracts of $C$. asiatica showed that there has inhibition process occur and visible of difference degrees of growth inhibition in difference fungal.

Based on the Table 1 and Figure 1aof antifungal activity for Aspergillus niger, it shows that there is not any inhibition zone visible in stems, roots, leaves, whole plants, water crude extracts and control. From the previous study, the Fluconazole and nystin is an antibiotic that can kill the fungal infection and grow (Brinkhaus et al., 2000). So, positive control should show an inhibition that kill the fungal instead of none. The negative results on the control show an error occur as the control must give positive result of zone inhibition. Table 2 and Figure 1b shows Penicillium sp. anti-fungal activity, the results above show that only control (Nystatin antibiotic) give a positive result which is visible of inhibition zone. No zone inhibition results visible on all parts of $C$. asiatica (stems, roots, leaves, whole plants, crude water extracts). Its shows that the part of $C$. asiatica do not have any antifungal properties to kill Penicillium sp. For the C. albicans, the figure 1c and table 3 above shows, there is a positive result as zone of inhibition is visible. From the observation, stems, roots, leaves, whole plant shows that they have an inhibitory property to against $C$. albicans. Compared to the other of water plant extract, both of control, which is nystatin in and fluconazole antibiotic give a negative result as no zone inhibition visible. Based on the previous study, both of this antibiotic are strong enough to kill the C. albicans but here there shows no inhibition.
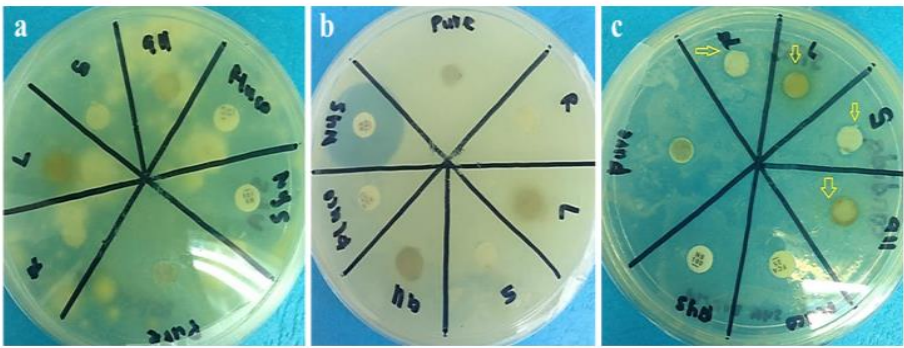

Figure 1 (a) Zone inhibition of Aspergillus niger niger (b) Zone of inhibition of Penicillium sp. (c) Zone of inhibition of Candida albicans

Table 1 Result of zone of inhibition of Aspergillus niger niger of methanolic extraction of Centella asiatica in difference parts.

Parts of Plants Positive

Roots

Stems

Leaves

Whole plants

Crude water

extract

Nystin

Fluconazole

-ve

Table 2 Result for zone of inhibition of Penicillium sp. of methanolic extraction of Centella asiatica in difference parts.

Parts of Plants Positive

Negative

Roots

Stems

Leaves

Whole plants

Crude water-

extract

Nystin

$\underline{\text { Fluconazole }}$ +ve 
Table 3 Result for zone of inhibition of Candida albicans of methanolic extraction of Centella asiatica in difference parts.

\begin{tabular}{lcc}
\hline Parts of Plants & Positive & Negative \\
\hline Roots & + & \\
Stems & + & \\
Leaves & + & \\
Whole plants & + & \\
Crude water extract & $-v e$ & \\
Nystin & & $-v e$ \\
Fluconazole & & $-v e$ \\
\hline
\end{tabular}

The broth dilution method is used to determine the growth rate of plant extracts. By using this method, the antifungal activity can be noticed even at low concentration. The result of this test revealed that the $C$. asiatica crude methanol extract have an antifungal property that can inhibit antifungal against $C$. albicans, Penicillium sp., and Aspergillus niger niger. All the part of Centella asiatica of the plant extract contain active compound that cause mitochondrial damage to the yeast (Gray et al., 2018; Ling et al., 2000).

\section{Growth Rate}

The broth dilution method is used to determine the inhibition process that presence during the time interval of plant extracts against fungal. By using this method, the antifungal activity can be noticed even at low concentration by observation the absorbance using spectrophotometer. The result of this test revealed that the $C$. asiatica methanol extract shows there have antifungal activity against $C$. albicans, Aspergillus niger, and Penicillium sp. All of the plant extract contains active compounds that cause mitochondrial damage to the yeast (Diallo, 1991; Guzewska et al., 2006). The difference between the antifungal activities towards difference part of Centella asiatica may be due the type of difference bioactive compounds in difference part of plant extracts such as stems, roots, leaves, whole plants and crude water extracts. This finding is supported by previous research (Rakotoniriana et al., 2008; Gupta, et al., 1999) who had found that the biological effects of the essential oils depend on the type and quantity of active compounds. The effectiveness against fungus of Centella asiatica oil is affected by their chemical compositions and compounds.

Table 4 Growth rate of Aspergillus niger in different parts of Centella asiatica plant samples

\begin{tabular}{lcccc}
\hline Time interval (minutes) & Roots & Stems & Leaves & $\begin{array}{c}\text { Whole } \\
\text { Plants }\end{array}$ \\
\hline 0 & 0.071 & 0.134 & 1.135 & 0.565 \\
30 & 0.067 & 0.112 & 0.957 & 0.411 \\
60 & 0.056 & 0.097 & 0.851 & 0.364 \\
90 & 0.054 & 0.081 & 0.727 & 0.235 \\
120 & 0.052 & 0.077 & 0.665 & 0.209 \\
150 & 0.049 & 0.072 & 0.592 & 0.180 \\
180 & 0.144 & 0.167 & 0.639 & 0.245 \\
\hline
\end{tabular}

From the table 4, it shows that the growth rate of Aspergillus niger in different parts of $C$. asiatica plants sample. From the graph, the growth curves (GC) of the fungi Aspergillus niger showed that the PDA medium at room temperature of $27^{\circ} \mathrm{C}$ well suited the in vitro assays in the cuvette. The each of the sample of stems, leaves, roots, and whole plants is observed from every 30 minutes interval from the first 0 minutes to the minutes of 180 . From the reading of table 4 above, the absorbance of all the part of $C$. asiatica did significantly affect fungal Growth Rate (GR) and markedly inhibited or completely prevented the growth of fungi tested.

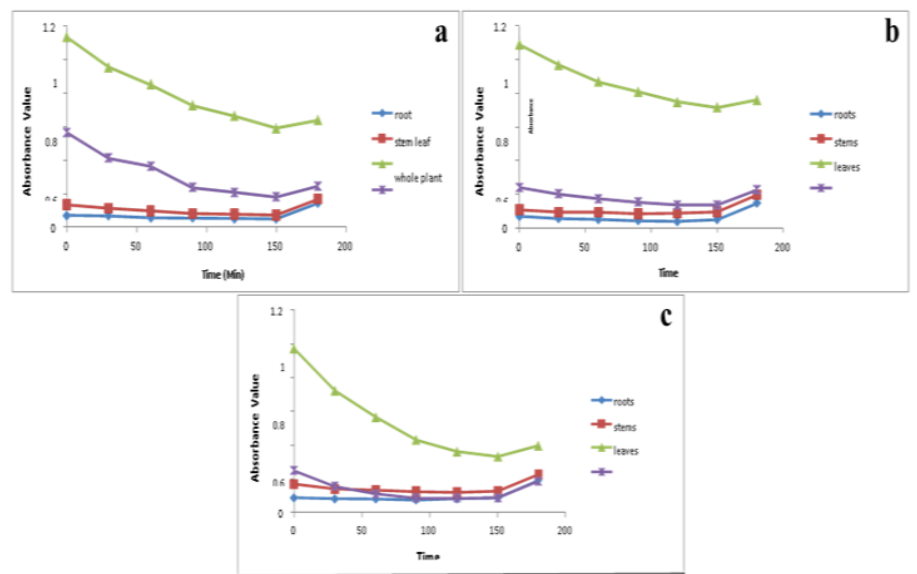

Figure 2 (a) Effect of different parts of Centella asiatica on Aspergillus niger (b) Effect of Different parts of Centella asiatica on Penicillium sp. (c) Effect of different parts of Centella asiatica on Candida albicans
From the table and figure $2 \mathrm{a}$ above the inhibition process continuing decreasing from 0 min until minutes of 150 . After minutes of 150 to minutes of 180 , the reading of absorbance is increased in all the parts of plants. A time-response relationship was generally observed for each fungus, with average fungal GR decreasing when the time is increased.

Figure $2 \mathrm{~b}$ above clearly shows the reduction of growth rate (GR) of Penicillium $\mathrm{sp}$., from minutes of 0 to minutes of 150 . It means that the bioactive compound in the stems, leaves, roots, and whole plants inhibit the fungi growth. It shows the plant of $C$. asiatica have an antifungal property in each of parts. When the time is increased from zero minutes to 150 minutes, the growth rate of the fungi is decrease, and is well depicted in figure $2 \mathrm{~b}$ above. There is growth actively occur in the minutes of 150 to minutes of 180 where the inhibition process of fungi is stop and start to increase. It is clearly stated at the table 5 above where it shows the reading absorbance of each sample of stem, leaves, roots and whole plants.

Table 5 Growth rate of Penicillium sp. in different parts of Centella asiatica plants sample

\begin{tabular}{lcccc}
$\begin{array}{l}\text { Time interval } \\
\text { (minutes) }\end{array}$ & roots & stems & leaves & Whole plants \\
\hline 0 & 0.071 & 0.109 & 1.089 & 0.242 \\
30 & 0.057 & 0.096 & 0.969 & 0.202 \\
60 & 0.052 & 0.095 & 0.868 & 0.175 \\
90 & 0.043 & 0.086 & 0.81 & 0.154 \\
120 & 0.04 & 0.089 & 0.75 & 0.138 \\
150 & 0.05 & 0.097 & 0.715 & 0.138 \\
180 & 0.147 & 0.198 & 0.761 & 0.227 \\
\hline
\end{tabular}

Table 6 Growth rate of Candida albicans in different parts of Centella asiatica plants sample

\begin{tabular}{lcccc}
\hline Time interval (minutes) & roots & stems & leaves & $\begin{array}{c}\text { whole } \\
\text { plants }\end{array}$ \\
\hline 0 & 0.089 & 0.17 & 0.971 & 0.248 \\
30 & 0.083 & 0.141 & 0.723 & 0.155 \\
60 & 0.081 & 0.133 & 0.567 & 0.112 \\
90 & 0.075 & 0.124 & 0.43 & 0.085 \\
120 & 0.083 & 0.12 & 0.362 & 0.085 \\
150 & 0.088 & 0.128 & 0.333 & 0.089 \\
180 & 0.191 & 0.226 & 0.398 & 0.187 \\
\hline
\end{tabular}

From the results below, it shows that growth rate of $C$. albicans towards $C$. asiatica extracts of stems, leaves, roots, and whole plants were tested against fungi. Therefore, the antifungal activities from all part of $C$. asiatica were tested using the same methods of broth dilution and was observed by measuring the growth rate process through absorbance measurement. It shows that all parts of stems, leaves, roots and whole plants can inhibit the process of fungi growth (Bhuyar et al., 2020d). It means that the $C$. asiatica have an antifungal property that can prevent the process of fungi from growth. From the table 6 , it is clearly stated the reading of absorbance is decrease when the time is increased. But in the minutes of 150 , the process of inhibition of fungal is depleted and start to growth back.

According to results obtained it shows that the growth rate of fungal Penicillium sp., Aspergillus niger, and C. albicans. The inhibitory effects of different part of $C$. asiatica such as stems, roots, leaves and whole plants on the growth rates (GR) of three pathogenic fungi (Aspergillus niger, C. albicans, Penicillium sp.) were examined using a cuvette and a spectrophotometer reader. The antifungal activity of the fungus is observed within 30 minutes interval. From that, we can see that all the part of $C$. asiatica showing a positive result as they can inhibit the fungal growth. So, it clearly shows that the bioactive component in the $C$. asiatica have an antifungal property in the stems, roots, leaves, and whole plant can inhibit the process of fungal growth as any compound with fungicidal properties could be potentially has inhibitory activity on fungal growth or sporulation. In the minutes of 150 , the growth of fungal seems continuing active and start to growth.

\section{Bioactive Compounds}

In the last few years gas-chromatography mass-spectrometry has become firmly established as a key technological platform for metabolite profiling in both plant and non-plant species (Bhuyar et al., 2019c). Until relatively recently only a limited number of plant research laboratories had access to gas-chromatography mass-spectrometry instrumentation, however, such machines are increasingly becoming more common place. The table 7 shows that the bioactive compound that presence in the Centella asiatica plant extract of methanol. The major compound is n-Hexadecanoic acid which percentage of 99. The second major compound presence is cis-Vaccenic acid at peak 8 with percentage 91. Followed by 5 -Hydroxymethylfurfural 88 precent, Tetradecanoic acid and so on. The identified compounds possess many biological properties. For instance, nHexadecanoic acid, cis-Vaccenic acid, 5-Hydroxymethylfurfural and Tetradecanoic acid Previously, 5-HMF known to exhibited novel antioxidant 
activity, also act as inhibitor that effect of 5-HMF on human cancer cell proliferation was investigated by MTT assay, flow cytometric analysis, and the TUNEL and DAPI costaining assay. It is displayed higher antiproliferative activity on human melanoma A375 cells than other cell lines poten antiangiogenic agent in colorectal cancer and in HUVEC cells. The other compounds such as n-Hexadecanoic acid, are reported to be antimicrobial.

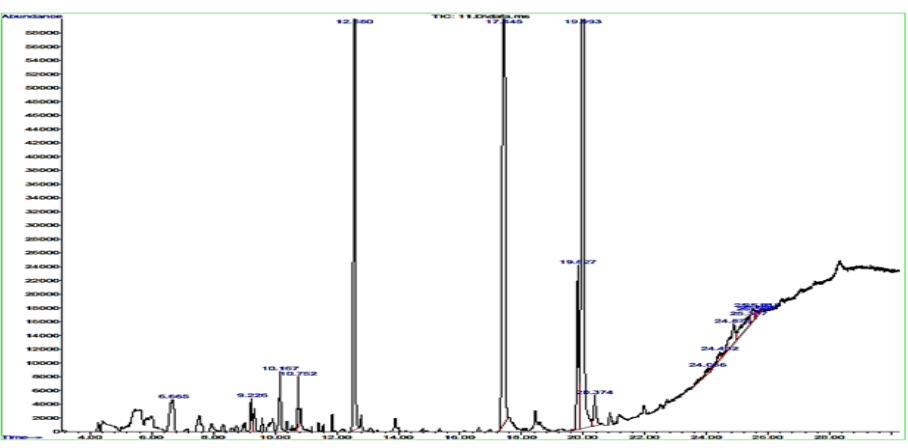

Figure 3 Total ionic chromatogram biological active compounds of methanolic extract of whole part of Centella asiatica

Table 7 Total ionic chromatogram biological active compound of methanol extract of whole plants of Centella asiatica

\begin{tabular}{lccc}
\hline Peak & $\begin{array}{c}\text { Retention } \\
\text { time }\end{array}$ & Compounds & Percentage \\
\hline 5 & 12.580 & 5- Hydroxymethylfurfural & 88 \\
6 & 17.443 & n-Hexadecanoic acid & 99 \\
7 & 19.829 & Tetradecanoic acid & 86 \\
8 & 19.995 & cis-Vaccenic acid & 91 \\
10 & 24.035 & $4,7,10,13,16-$ Pentaoxanonadeca- & 78 \\
& 24.430 & 2,5,8,18122476058185-54-9 78-diene & 64 \\
11 & 24.876 & Propane, 1,2,3-trimethoxy- & 53 \\
12 & 25.374 & Silane, methylenebis & 64 \\
13 & 25.517 & 15-Crown-5 & 64 \\
14 & 25.809 & $3,6,9,12-$ Tetraoxatetradecan-1- ol & 56 \\
17 & &
\end{tabular}

By referring and comparing with the previous research, we can determine the substances presence in the $C$. asiatica that act as therapeutic interest are the saponin- containing triterpene acids and their sugar esters, the most important being: asiatic acid, madecassic acid and the three asiaticosides, asiaticoside, asiaticoside A and asiaticoside B (Brinkhaus et al. 2000; Devkota et al., 2010) The structures of the three triterpenoid trisaccharides asiaticoside, asiaticoside-A and asiaticoside- $\mathrm{B}$, have been elucidated by spectroscopic analysis as the $[\mathrm{O}-\beta-\mathrm{L}$ rhamnopyranosyl- $(1 \rightarrow 4)-O-\beta$-D-glucopyranosyl $(1 \rightarrow 6)]-O-\beta$ - glucopyranose esters of $2 \beta, 3 \beta, 23 \beta$-trihydroxy-urs-12-ene-28-oic acid, of $2 \beta, 3 \beta, 6 \beta, 23 \mathrm{v}$ tetrahydroxy-urs-12-ene-28-oic acid and of $2 \beta, 3 \beta, 6 \beta, 23 \beta$-tetrahydroxyolean- 12 ene- 28-oic acid (Devkotal et al., 2010). The main active principles of $C$ asiatica, are the triterpenoids glycosides asiaticoside and madecassoside (asiaticoside A), used for the quantification of this species as described in the European Pharmacopoeia, and their respective aglycons (asiatic acid and madecassic acid). Significant differences in active constituent contents have been observed between samples of Centella asiatica originating from different countries (Chen et al., 2007). Depending on the source of the material, the amount of the triterpenoids may vary widely from $1 \%$ to $8 \%$. Fig. 1 (Brinkhaus et al., 2000) As a conclusion, by comparing the result of previous research and this research, less similarity of the compound presence in this experiment maybe due to improper procedure.

\section{CONCLUSION}

Thousands of years, human utilize plant extracts and essential oil in daily life as natural remedy against various infections. Until today, it is widely used in food preservation and pharmaceuticals alternative medicine. The anti-fungal activity of $C$. asiatica were tested against C. albicans, Aspergillus niger, and Penicillium sp. using two methods, disc diffusion method and broth dilution method. $C$. asiatica crude methanol extract was found to be the most effective against fungal activity. Compared to disc diffusion, broth dilution was a more appropriate method to quantitatively determine the anti-Candida activity of plant extract, whereby the MIC values of the crude extracts can be determined. The result from disc diffusion assay demonstrates that plant extracts have an inhibitory effect. However, the broth dilution method result reveal that $C$. asiatica crude methano extract has lower MIC values, meaning it has more prove that $C$. asiatica has an anti-fungal effect. In conclusion, $C$. asiatica crude methanol extract was found to be a as antifungal agent against fungal infection especially $C$. albicans, Aspergillus niger, and Penicillium spp. Hence, it represents an alternative source of natural antifungal substances.
Acknowledgments: The authors gratefully acknowledged Universiti Malaysia Pahang for the financial assistance through the Internal Research Grant No. RDU190337/ RDU1903125 and Flagship Grant No. RDU182205. Author [Prakash Bhuyar] is thankful to UMP for providing Doctoral Research Scholarship DRS as a financial support.

\section{REFERENCES}

Bhuyar, P. (2017). Isolation, Partial Purification and Characterization of Protease Enzyme from Proteolytic Bacteria from Dairy Soil. International Journal for Research in Applied Science \& Engineering Technology (IJRASET), 5(Xi), 4083-4095. www.ijraset.com4083

Bhuyar, P., Rahim, M. H. A., Sundararaju, S., Ramaraj, R., Maniam, G. P., \& Govindan, N. (2020a). Synthesis of silver nanoparticles using marine macroalgae Padina sp. and its antibacterial activity towards pathogenic bacteria. Beni-Suef University Journal of Basic and Applied Sciences, 9(1), 1-15 https://doi.org/10.1186/s43088-019-0031-y

Bhuyar, P., Rahim, M.H.A., Yusoff M. M., Maniam, G. P., Govindan N., (2019a). A selective microalgae strain for biodiesel production in relation to higher lipid profile. Maejo International Journal of Energy and Environmental Communication, $1(1)$ http://www.mijeec.mju.ac.th/Upload/Journal/9060116f-7fa6-4c61-82b1cd5a3400cdb9.pdf

Bhuyar, P., Sathyavathi, S., K Math, R., Pragas Maniam, G., \& Govindan, N. (2020b). Production of bioethanol from starchy tuber (Amorphophallus commutatus) and antimicrobial activity study of its extracts. African Journal of Biological Sciences, 2(2), 70-76. https://doi.org/10.33472/AFJBS.2.2.2020.70-76 Bhuyar, P., Sundararaju, S., Rahim, M. H. A., Ramaraj, R., Maniam, G. P., \& Govindan, N., (2019b). Microalgae cultivation using palm oil mill effluent as growth medium for lipid production with the effect of CO 2 supply and light intensity. Biomass Conversion and Biorefinery 1 9.https://doi.org/10.1007/s13399-019-00548-5

Bhuyar, P., Rahim, M. H., Sundararaju, S., Maniam, G. P., \& Govindan, N. (2020c). Antioxidant and antibacterial activity of red seaweed Kappaphycus alvarezii against pathogenic bacteria. Global Journal of Environmental Science and Management, 6(1), https://doi.org/47-58. 10.22034/GJESM.2020.01.04

Bhuyar, P., Tamizi, N. A. B. M., Rahim, M.H.A., Yusoff M. M., Maniam, G. P., Govindan N., (2019c). Effect of ultraviolet light on the degradation of LowDensity and High- Density Polyethylene characterized by the weight loss and FTIR. Maejo International Journal of Energy and Environmental

Communication, $1(2)$,
http://www.mijeec.mju.ac.th/Upload/Journal/37513dc2-7d00-42f8-9c1b-

78c1afea0b2f.pdf

Bhuyar, P., Yusoff, M. M., Rahim, M. H. A., Sundararaju, S., Maniam, G. P., \& Govindan, N. (2020d). EFFECT OF PLANT HORMONES ON THE PRODUCTION OF BIOMASS AND LIPID EXTRACTION FOR BIODIESEL PRODUCTION FROM MICROALGAE Chlorella Sp. Journal of Microbiology, $\begin{array}{llll}\text { Biotechnology and Food Sciences, 9(4), 671-674 } & \end{array}$ https://doi.org/10.15414/jmbfs.2020.9.4.671-674

Bhuyar, P., Zagade S., Revankar, R., Yusoff, M. M., Rahim, M. H. A., Govindan N., (2018). Isolation, Characterization and Partial Purification of Keratinase from Keratinolytic Bacteria. Scholar Journal of Applied Sciences and Research, 1(6), 40-45. www.innovationinfo.org

Booncong P., Linder M., Schuppan D., and Hahn E.G. (2000). A Pharmacognostic and Taxonomic Study of Centella asiatica Apiaceae. PhD Thesis, Miami University, Ohio, USA.

Borhan, M. Z., Ahmad, R., Rusop, M., \& Abdullah, S. (2013). Impact of nanopowders on exraction yield of Centella asiatica. In Advanced Materials Research (Vol. 667, pp. 246-250). Trans Tech Publications Ltd https://doi.org/10.4028/www.scientific.net/AMR.667.246

Brinkhaus, B., Lindner, M., Schuppan, D., \& Hahn, E. G. (2000). Chemical, pharmacological and clinical profile of the East Asian medical plant Centella aslatica. Phytomedicine, 7(5), 427-448. https://doi.org/10.1016/S0944 7113(00)80065-3

Chen, L., Ding, L., Yu, A., Yang, R., Wang, X., Li, J., ... \& Zhang, H. (2007) Continuous determination of total flavonoids in Platycladus orientalis (L.) Franco by dynamic microwave-assisted extraction coupled with on-line derivatization and ultraviolet-visible detection. Analytica chimica acta, 596(1), 164-170 https://doi.org/10.1016/j.aca.2007.05.063

Cushnie, T. T., \& Lamb, A. J. (2005). Antimicrobial activity of flavonoids. International journal of antimicrobial agents, 26(5), 343-356 https://doi.org/10.1016/j.ijantimicag.2005.09.002

Devi, N. N., \& Prabakaran, J. J. (2014). Bioactive metabolites from an endophytic fungus Penicillium sp. isolated from Centella asiatica. Curr Res Environ Appl Mycol, 34-43. https://pdfs.semanticscholar.org/2e4b/f22aeefdbfabb5675e08a9743d541935c89b. pdf

Devkota, A., Dall'Acqua, S., Comai, S., Innocenti, G., \& Jha, P. K. (2010) Centella asiatica (L.) urban from Nepal: quali-quantitative analysis of samples 
from several sites, and selection of high terpene containing populations for cultivation. Biochemical Systematics and Ecology, 38(1), 12-22. https://doi.org/10.1016/j.bse.2009.12.019

Diallo, B., Vanhaelen-Fastré, R., \& Vanhaelen, M. (1991). Direct coupling of high-speed counter-current chromatography to thin-layer chromatography: Application to the separation of asiaticoside and madecassoside from Centella asiatica. Journal of Chromatography A, 558(2), 446-450 https://doi.org/10.1016/0021-9673(91)80013-7

Gray, N. E., Magana, A. A., Lak, P., Wright, K. M., Quinn, J., Stevens, J. F., ... \& Soumyanath, A. (2018). Centella asiatica: Phytochemistry and mechanisms of neuroprotection and cognitive enhancement. Phytochemistry Reviews, 17(1), 161-194. https://doi.org/10.1007/s11101-017-9528-y

Gupta, A. P., Gupta, M. M., \& Kumar, S. (1999). High performance thin layer chromatography of asiaticoside in Centella asiatica. Journal of the Indian Chemical Society, 76(6), 321-322.

Guzewska J, Skopińska-Różewska E, Mścisz A, Buchwald W, Białas-Chromiec B, Filewska M, Furmanowa M. (2006). Selected biological activities of Centella asiatica extracts. 5th International Symposium on Chromatography of Natural Products Lublin, 19-22:105.

Hamid, A. A., Shah, Z. M., Muse, R., \& Mohamed, S. (2002). Characterisation of antioxidative activities of various extracts of Centella asiatica (L) Urban. Food chemistry, 77(4), 465-469. https://doi.org/10.1016/S0308-8146(01)00384-3

Inamdar, P. K., Yeole, R. D., Ghogare, A. B., \& De Souza, N. J. (1996) Determination of biologically active constituents in Centella asiatica. Journal of Chromatography A, 742(1-2), 127-130. https://doi.org/10.1016/0021 9673(96)00237-3

Jagtap, N. S., Khadabadi, S. S., Ghorpade, D. S., Banarase, N. B., \& Naphade, S S. (2009). Antimicrobial and antifungal activity of Centella asiatica (L.) Urban, Umbeliferae. Research Journal of Pharmacy and Technology, 2(2), 328-330.

Khammee, P., Ramaraj, R., Whangchai, N., Bhuyar, P., \& Unpaprom, Y. (2020)

The immobilization of yeast for fermentation of macroalgae Rhizoclonium sp. for efficient conversion into bioethanol. Biomass Conversion and Biorefinery, i. https://doi.org/10.1007/s13399-020-00786-y

Li, Y., Liu, K., Wang, Y., Zhou, Z., Chen, C., Ye, P., \& Yu, F. (2018) Improvement of cadmium phytoremediation by Centella asiatica L. after soil inoculation with cadmium-resistant Enterobacter sp. FM-1. Chemosphere, 202, 280-288. https://doi.org/10.1016/j.chemosphere.2018.03.097

Ling, A. P. K., Marziah, M., \& Tan, S. E. (2001). Triterpenoids distribution in whole plant and callus cultures of Centella asiatica accessions. In Interdisciplinary approaches in natural products research: proceedings of the 16th National Seminar on Natural Products. Dept. of Chemistry, University Putra Malaysia.

Loiseau A, Thēron E, Buche P, Sirvent A, Girard F. 2002. Evidencing the antimicrobial properties of Centella asiatica. Euro Cosmet. 4:20-2.

Rakotoniriana, E.F., Munaut, F., Decock, C. et al. Endophytic fungi from leaves of Centella asiatica: occurrence and potential interactions within leaves. Antonie van Leeuwenhoek 93, 27-36 (2008). https://doi.org/10.1007/s10482-007-9176-0

Ramli, A.N.M., Manap, N.W.A., Bhuyar, P., Azelee, N. I. W., (2010). Passion fruit (Passiflora edulis) peel powder extract and its application towards antibacterial and antioxidant activity on the preserved meat products. SN Appl. Sci. 2, 1748. https://doi.org/10.1007/s42452-020-03550-Z

Saengsawang, B., Bhuyar, P., Manmai, N., Ponnusamy, V. K., Ramaraj, R., \&

Unpaprom, Y. (2020). The optimization of oil extraction from macroalgae, Rhizoclonium sp. by chemical methods for efficient conversion into biodiesel. Fuel, 274, 117841.https://doi.org/10.1016/j.fuel.2020.117841

Sampson, J. H., Raman, A., Karlsen, G., Navsaria, H., \& Leigh, I. M. (2001). In vitro keratinocyte antiproliferant effect of Centella asiatica extract and triterpenoid saponins. Phytomedicine, 8(3), 230-235. https://doi.org/10.1078/0944-7113-00032

Zainol, M. K., Abd-Hamid, A., Yusof, S., \& Muse, R. (2003). Antioxidative activity and total phenolic compounds of leaf, root and petiole of four accessions of Centella asiatica (L.) Urban. Food Chemistry, 81(4), 575-581. https://doi.org/10.1016/S0308-8146(02)00498-3

Zainol, N. A., Voo, S. C., Sarmidi, M. R., \& Aziz, R. A. (2008). Profiling of Centella asiatica (L.) Urban extract. Malaysian Journal of Analytical Sciences, 12(2), 322-327. 